\title{
The Conceptual Design of a Continuous Pervaporation Membrane Reactor for the Production of 1,1-Diethoxy Butane
}

\author{
I. Agirre ${ }^{1}$ \\ M. Belén Güemez ${ }^{1}$ \\ A. Motelica \\ H.M. van Veen \\ J.F. Vente \\ P.L. Arias ${ }^{1}$ \\ ${ }^{1}$ Dept. of Chemical and Environmental Engineering, Engineering School of Bilbao (UPV/EHU), 48013 Bilbao, Spain
}




\title{
The Conceptual Design of a Continuous Pervaporation Membrane Reactor for the Production of 1,1-Diethoxy Butane
}

\author{
Ion Agirre \\ Dept. of Chemical and Environmental Engineering, Engineering School of Bilbao (UPV-EHU), Bilbao 48013, Spain \\ Dept. of Efficiency \& Infrastructure Unit, Energy Research Centre of the Netherlands, Petten 1755 ZG, The Netherlands \\ M. Belén Güemez \\ Dept. of Chemical and Environmental Engineering, Engineering School of Bilbao (UPV-EHU), Bilbao 48013, Spain \\ Anatolie Motelica, Henk M. van Veen, and Jaap F. Vente \\ Dept. of Efficiency \& Infrastructure Unit, Energy Research Centre of the Netherlands, Petten 1755 ZG, The Netherlands \\ Pedro L. Arias \\ Dept. of Chemical and Environmental Engineering, Engineering School of Bilbao (UPV-EHU), Bilbao 48013, Spain
}

DOI 10.1002/aic.12692

Published online in Wiley Online Library (wileyonlinelibrary.com).

\begin{abstract}
Acetals are considered as an important bio-based diesel additives. Generally, the catalytic production of these compounds from an alcohol and an aldehyde suffers from a low conversion because of thermodynamic limitations. These limitations can be overcome through the in situ removal of the by-product water using, for example, a water selective membrane. A critical evaluation on the membrane performance, catalyst activity, optimal configuration, and feed composition leads to the conclusion that a combined reaction and separation is unlikely to be advantageous. The water permeance of the selected membrane was assessed to be too low in relation with the catalyst activity. (C) 2011 American Institute of Chemical Engineers AIChE J, 00: 000-000, 2011
\end{abstract}

Keywords: acetals, membrane reactor design, modeling, fuel additive, HybSi $\mathbb{R}$

\section{Introduction}

Acetals are considered as an important bio-based diesel additives. ${ }^{1}$ The mixibility of these oxygenated compounds with (bio)diesel is satisfactory and their usage results in lower emissions of particulate matter and nitrogen oxides, $\mathrm{NO}_{x}$. 1,1-Diethoxy butane is one of the acetals that fulfills all diesel specifications. An alternative could be the 1,1-diethoxy ethane. This lighter compound is, however, less suitable as the flash point $(252 \mathrm{~K})$ is well below the diesel

\footnotetext{
Correspondence concerning this article should be addressed to I. Agirre at ion. agirre@ehu.es.
}

(C) 2011 American Institute of Chemical Engineers specification value of $328 \mathrm{~K}$. 1,1-Diethoxy butane can be produced from bio-based ethanol and butanal. Fermentation of biomass is a direct method for the production of ethanol, whereas dehydrogenation or partial oxidation of $n$-butanol (also a biomass fermentation product) is a suitable process for the production of butanal.

Common homogeneous catalysts for acetalization reactions are mineral acids, such as $\mathrm{H}_{2} \mathrm{SO}_{4}, \mathrm{HF}, \mathrm{HCl}$, and $p$-toluene sulfonic acid. ${ }^{2-4}$ The intrinsic disadvantages of these catalysts are their corrosive and environmental properties. The novel solid acid catalysts from commercial, natural, and laboratory sources do not suffer from these drawbacks. ${ }^{1}$ The most promising candidate out of this class of catalysts are ion exchange resins. 
In recent years, there has been an increasing interest in developing advanced processes, where the reaction and separation are combined in one single unit. These systems can help overcoming the thermodynamically limited equilibrium conversions that are typical for esterification and acetalization reactions. ${ }^{1,5-8}$ Dehydration membrane reactors are among the most promising alternatives in this kind of reactions. The continuous in situ water removal from the reaction mixture shifts the reaction toward product formation. ${ }^{9-15}$ Sanchez Marcano and Tsotsis ${ }^{16}$ were among the first to describe the advantages of a membrane reactor for the applications. More recently, Drioli and Giorno ${ }^{17}$ have published an extensive work on membrane phenomena including state-of-the-art on pervaporation membrane reactors.

Most publications on this topic focus on lab scale experiments and the modeling thereof in batch operations. ${ }^{14,15,18-22}$ Only a small amount of publication deals with continuous processes. Zhu et al. ${ }^{9}$ combined experimental and modeling experiment for a continuous tubular pervaporation membrane reactor for esterification reactions using $\mathrm{H}_{2} \mathrm{SO}_{4}$ as homogeneous catalyst. de la Iglesia et al. ${ }^{23}$ also performed esterification reactions experiments in a continuous tubular reactor. In this case, Amberlyst 15 was used as catalyst. Lim et al. ${ }^{11}$ studied different process configurations and demonstrated the advantages of a tubular membrane reactor a over stirred tank membrane reactors. The results of Nemec and Van Gemert ${ }^{24}$ on multifunctional tubular reactors were not very satisfactory.

Some time ago, we have embarked on an extensive program on different possibilities of the industrial production of the acetal 1,1-diethoxy butane. The initial focus was focused on reactive distillation. The main conclusion was that thermodynamic limitations could be overcome. However, small differences in volatility resulted in a small increase in final conversions. ${ }^{25}$ More recently, the use of batch membrane reactors based on $\mathrm{HybSi}^{\circledR}$ technology ${ }^{26}$ was proven to result in a large increase in conversion. This is a prime requirement to come to a commercially interesting process and has shown the feasibility of the usage of membranes for this process. Currently, the possibilities of moving to a continuous process are discussed. The first step is the conceptual design of a pervaporation membrane reactor, which is the focus of this paper.

\section{Membrane Reactor Modeling Reaction kinetics}

The reaction under consideration is the acetalization of ethanol (A) and butanal (B) to produce 1,1-diethoxy butane (C) and water (D)

$$
2 \mathrm{C}_{2} \mathrm{H}_{6} \mathrm{O}(\mathrm{A})+\mathrm{C}_{4} \mathrm{H}_{8} \mathrm{O}(\mathrm{B}) \Leftrightarrow \mathrm{C}_{8} \mathrm{H}_{18} \mathrm{O}_{2}(\mathrm{C})+\mathrm{H}_{2} \mathrm{O}(\mathrm{D})
$$

Like most of the acetalization reactions, this reaction is exothermic with low equilibrium conversions, ${ }^{27}$ and as for any exothermic reaction, the conversion increases with decreasing the temperature. The pressure has a very minor influence on the equilibrium conversion operating in liquid phase. Acid catalysts typically catalyze the reaction, and four different Amberlyst resins (15wet, 35wet, 70 and 47) were selected for this study. A pseudohomogeneous kinetic model (Eq. 1) can well describe the behavior of the reaction. ${ }^{27}$

$$
\frac{d[C]}{d t}=w k_{1}[B][A]^{2}-w k_{2}[C][D]
$$

The performance of the four catalysts was shown to be very comparable at the chosen operating conditions, and all the kinetic parameters are well known. ${ }^{27}$ The literature data will be used throughout this paper for the simulations.

\section{Membrane transport}

The transport equation for a certain component through the membrane was based on Fick's Law as described in the literature. ${ }^{28,29}$

$$
f_{i}=Q_{i}\left(x_{i} \gamma_{i} P_{i}^{\mathrm{sat}}-y_{i} P^{\mathrm{perm}}\right)
$$

The saturation pressure, $P^{\text {sat }}$, of each component was calculated with Antoine's equations. ${ }^{30}$ Activity coefficients were calculated with the non-random two-liquid (NRTL) model for the relevant mixtures. ${ }^{31}$ Permeance data $(Q)$ for the various components for the HybSi membrane were determined from ethanol/butanal/1,1-diethoxy butane/water batch dehydration experiments, and validated using a batch model. ${ }^{26}$ Relation (2) shows that the absolute pressure on the feed side has a minimal impact on the flux of the permeating species. The temperature on the other hand does have a major influence on the flux, and this aspect has been taken into account in the modeling work. ${ }^{26}$

\section{Modeling a multitubular plug flow membrane reactor}

For the integration of a pervaporation membrane into the acetal production reactor a multitubular membrane reactor was selected, in which reaction and separation take place in the same unit. In the development of the model to describe such a reactor, the following assumptions were made:

- The reactor behaves as an ideal plug flow reactor (PFR).

- A pseudohomogeneous kinetic model is assumed.

- The membrane is completely inert and does not influence the reaction kinetics.

- Concentration polarization and temperature polarization are negligible.

- The selective membrane layer is on the outside (shell side) of the membrane tube.

- The permeate side is perfectly mixed.

- Permeance values depend only on the temperature, and not on the composition of the mixture.

For future reference and comparison all the simulations were performed with a fixed flow rate of $7 \mathrm{~L} / \mathrm{h}$ : the same as what has been used in the semipilot experimental facilities for the reactive distillation tests. ${ }^{25}$

Based on the above assumptions, the model (3) describing the multitubular plug flow membrane reactor (MPFMR, Figure 1) consists of four molar balances along the shell side, one for each component. The first term of the balance is related to the reaction and the second one to the mass transport through the membrane

$$
\frac{d F_{i}}{d z}=L\left(A_{\mathrm{t}} r_{i}-f_{i} p_{\mathrm{m}}\right)
$$


(a)

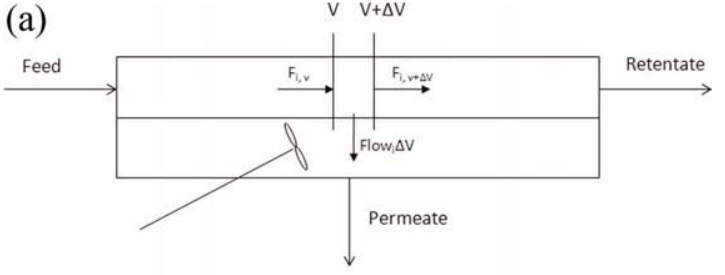

(b)

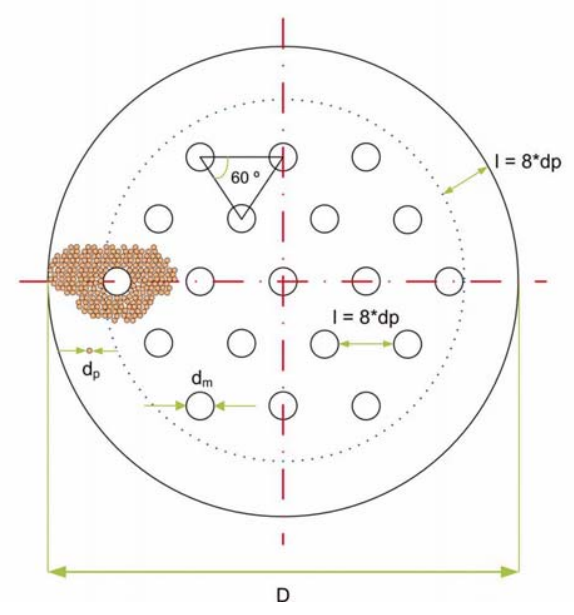

Figure 1. (a) The basic concept of the MPFMR and (b) cross section with main geometric characteristics.

[Color figure can be viewed in the online issue, which is available at wileyonlinelibrary.com.]

The membrane reactor was operated as an adiabatic system, which is at an industrial scale more common than the isothermal system. Further, the considered reaction is exothermic and the generated heat can be used to compensate for the endothermic pervaporation process. Further, an increased temperature is beneficial for both the reaction kinetics and the membrane flux.

The theoretical enthalpy of reaction (4) is estimated using the formation enthalpies of ethanol, butanal and water. ${ }^{32}$ For 1,1-diethoxy butane the formation enthalpy is retrieved from Aspen property estimation system.

$$
\Delta H_{\mathrm{r}}\left(T_{i}\right)=-31 \times 10^{3}-73\left(T_{i}-298.15\right)[\mathrm{kJ} / \mathrm{kmol}]
$$

The energy balance of the reactor, differentiated over the length, is given by relation (5). The second term of the numerator, which is related to the transport through the membrane, is the only difference with respect to an energy balance relation for a conventional plug flow tubular reactor.

$$
\frac{d T}{d z}=\frac{\left[A_{\mathrm{t}}\left(-\Delta H_{\mathrm{r}}(T)\right)\left(-r_{\mathrm{B}}\right)-N \pi d_{0}\left(J\left|\bar{\lambda}_{i}(T)\right|\right)\right] L}{\sum\left(F_{i} C_{\mathrm{p}, i}\right)}
$$

Although the pressure drop does not affect the overall process, it is convenient to calculate the pressure in the output (retentate stream), to estimate the requirements for pressurizing for further processing. In addition, it is an important parameter to ensure that the mixture on retentate side remains a liquid phase in all cases. The pressure drop is calculated using the Ergun equation (6). ${ }^{33}$

$$
\frac{d P_{\mathrm{F}}}{d z}=L\left[\frac{150 \mu(1-\varepsilon)^{2} v_{\mathrm{s}}}{\phi \varepsilon^{3} d_{\mathrm{p}}^{2}}+\frac{1.75(1-\varepsilon) v_{\mathrm{s}}^{2} \rho}{\phi \varepsilon^{3} d_{\mathrm{p}}}\right] \times 10^{-5}
$$

The void fraction or packed bed porosity $(\varepsilon)$ is influenced by the effects of the confining walls on the packing structure. Given an infinitely large container, the porosity of a randomly packed bed of spheres is $\sim 0.4$. Near the walls, the void fraction increases due to the contact point requirements between the wall and a sphere. ${ }^{34}$ Theuerkauf et al. developed a model to predict the void fraction in a packed bed taking into account particle properties, friction coefficients, and so forth. However, for relatively small particle, $d / D$ (particle diameter/ reactor diameter) $<0.5$, the simpler Dixon's correlation for spheres $^{35}$ (Eq. 7) can be used. In the present case, the reactor diameter was substituted by the hydraulic diameter.

$$
\varepsilon=0.4+0.05 \frac{d}{D}+0.412\left(\frac{d}{D}\right)^{2} \quad \frac{d}{D}<0.5
$$

This relation can be used to estimate the porosity resulting from the finite dimensions of the shell and the placement of different membrane tubes. The amount of catalyst loaded in the reactor can be seriously underestimated, especially when there is also a large amount of membranes present within the shell. Further, also the hydrodynamics will be affected, as the existence of large low void fraction areas would result in large preferential flow area, and the plug flow assumption would not be obeyed.

\section{Hydrodynamics/polarization effects}

In the current model, concentration and temperature polarization effects are not taken into account. The validity of these assumptions has been proven by the batch reactors analyses. Comparison between experimental and modeling data showed perfect agreement. ${ }^{26}$ This is in agreement with the findings by Sommer ${ }^{36}$ who found a limited influence of polarization effects. The origin of the concentration polarization can be found in the selective transport of water through the membrane. As a result, the water may be depleted from the bulk toward the membrane. ${ }^{36}$ Temperature polarization is a consequence of the evaporation that occurs over the membrane. The necessary vaporization enthalpy is taken from the energy of bulk fluid on retentate side decreasing the mixture temperature toward the membrane surface. Further precautions have been taken to limit the possible effects.

In a laminar flow regime and at high membrane permeances these effects can be significant resulting in a decreased pervaporation efficiency. ${ }^{36}$ Sommer et al. ${ }^{36}$ concluded that, for an annular duct module type, there is steep efficiency increase at $\mathrm{Re}=2300$ (limit between the laminar and transition zone). For this reason the feed will be kept in the transition flow regime throughout this study. In our case, this means that the actual module efficiency is $\sim 90 \%$, leading to an acceptable small underestimation of the membrane area needed. In the present case, the shell side of the module is filled with catalyst particles, similar to fixed catalytic beds. As a consequence the Reynolds number is calculated using the catalyst particle diameter as given in (8). ${ }^{33}$ 
Table 1. Two Initial Promising Reactor Configurations

\begin{tabular}{lcc}
\hline & Configuration 1 & Configuration 2 \\
\hline Shell diameter $(\mathrm{mm})$ & 22 & 58 \\
Membrane tube diameter $(\mathrm{mm})$ & 14 & 14 \\
Number of membrane tubes & 1 & 7 \\
Specific membrane area $\left(\mathrm{m}^{2} / \mathrm{m}^{3}\right)$ & 194 & 197 \\
Conversion & 0.44 & 0.66 \\
$\operatorname{Re}$ & $15-18$ & $1.5-2.5$ \\
\hline
\end{tabular}

$$
\operatorname{Re}=\frac{d_{p} v \rho}{(1-\varepsilon) \mu}
$$

As a result also the limits of the laminar and turbulent regimes change. ${ }^{37}$ The transition flow regime starts at $\mathrm{Re}=10$, and all the simulations were performed above this transition Re value.

\section{Simulation Results}

To ensure that the simulations were in the transition flow regime, an initial module design was made and the maximum membrane area that can be placed per cubic meter of catalyst bed was calculated. The membrane reactor design is inspired on the design of a shell-and-tube heat exchanger. The membrane tubes, analogous to the pipes in the heat exchanger, can be placed in different layouts. The equilateral triangular layout was selected as this offers the highest specific membrane area in $\mathrm{m}^{2} / \mathrm{m}^{3}$ (see Figure $1 \mathrm{~b}$ ).

The distance between the pipes in a heat exchanger is typically 1.25 times the outer diameter of the pipe. However, as discussed above the presence of catalyst has to be taken into account as well. To avoid the formation of preferential transport pathways for the liquid flow and to assure an intimate contact between reactants and catalyst particles surface, the distances between pipes and between pipes and the shell wall should be at least eight times the particle diameter. ${ }^{38,39}$ Figure $1 \mathrm{~b}$ shows the geometrical characteristics of the pervaporation reactor. The number of membrane pipes that can be placed in a certain module diameter was calculated for different commercially available membrane tube diameters and the particle size of four different Amberlyst resins (15wet, 35 wet, 70 and 47). The optimal configuration was that in which the specific membrane area is maximized while obeying the demands set on distances as explained above. This optimal configuration consists of membrane tubes with an outer diameter of $14 \mathrm{~mm}$ and Amberlyst 70 catalyst with a particle diameter of $0.5 \mathrm{~mm}$ (see Table 1). If one single membrane tube is used the achieved conversion is close to the equilibrium conversion. ${ }^{27}$ More parallel membranes lead to a large shell diameter and a too low Reynolds value.

All these preliminary simulations were performed under the same conditions: stoichiometric feed ratio $(\mathrm{EtOH} /$ butanal $2: 1$ in moles) at $70^{\circ} \mathrm{C}$, feed volumetric flow rate of $7 \mathrm{~L} / \mathrm{h}$, catalyst loading: $550 \mathrm{~g} / \mathrm{L}$ (packed bed density), permeate pressure: $500 \mathrm{~Pa}, 1 \mathrm{~m}$ of reactor length.

\section{Detailing the design of MPFMR}

In the remainder of this study, Configuration 1 will be used as a basis. The results obtained can be easily translated to a multimembrane system by increasing the flow to reach a similar Re. To study the effect of different variables on the process a sensitivity analysis was performed. The investigated variables were

- Reactor length: an increased length is expected to result in higher conversions as the membrane area increases, and more water can be removed as the residence time increases. However, the pressure drop on the feed-retentate side can increase.

- Temperature: a higher temperature leads to faster membrane permeation and reaction kinetics. The equilibrium conversion, however, is not favored

- Catalyst loading and membrane performance: the amount of catalyst and membrane area has to be well balanced, so that both steps are close to being rate delimiting. Otherwise, either too much area or too much catalyst is being used.

- Feed composition: excess of one of the reactants shifts the reaction toward the forward direction resulting in higher conversions

The results of these studies will be discussed in detail later.

\section{Length of the reactor}

Figure 2 shows the effect of the reactor length on the conversion and retentate pressure. All these simulations were performed with the stoichiometric feed ratio (2:1 see reaction scheme 1), feed temperature of $70^{\circ} \mathrm{C}$ a feed pressure of $0.3 \mathrm{MPa}$, a permeate pressure of $500 \mathrm{~Pa}$, and a catalyst loading of $550 \mathrm{~g} / \mathrm{L}$. Under these conditions the equilibrium conversion of the reaction without membranes is $39 \% .{ }^{27}$ As expected the conversion increases with increasing reactor length and reaches a maximum value of $74 \%$ at $15 \mathrm{~m}$. This maximum conversion is consistent with that experimentally obtained in a batch reactor using a HybSi membrane. ${ }^{26}$ The pressure drop in the packed bed reactor increases approximately linearly with the reactor length. Although the conversion and the pervaporation process are essentially

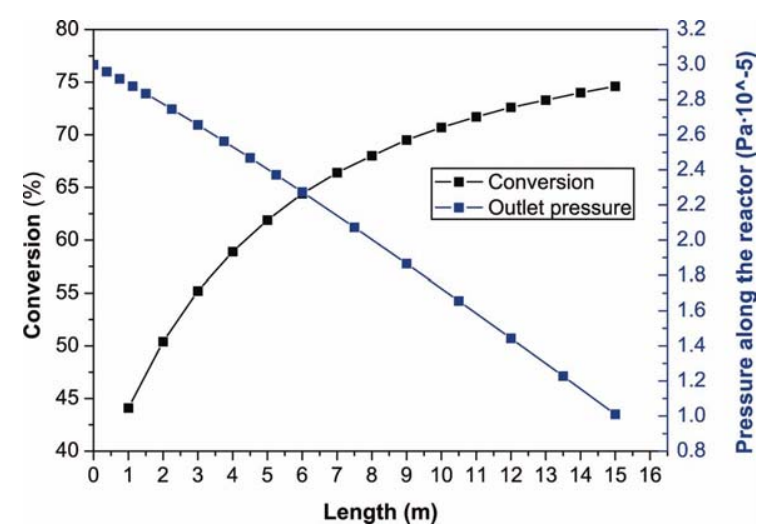

Figure 2. Conversion and retentate pressure as a function of the reactor length.

Conditions: $500 \mathrm{~g} / \mathrm{L}$ of A70, feed temperature: $70^{\circ} \mathrm{C}$, stoichiometric feed ratio, adiabatic reactor. (Equilibrium conversion at these conditions is 39\%.) [Color figure can be viewed in the online issue, which is available at wileyonlinelibrary.com.] 


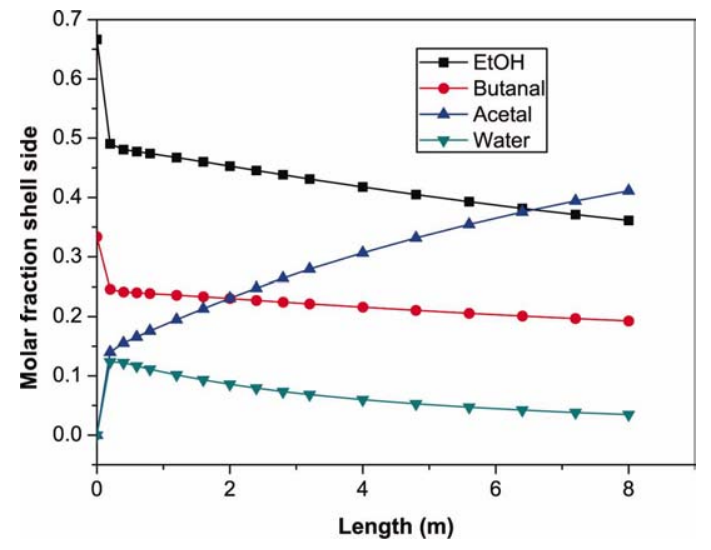

Figure 3. Molar fraction profile on the feed side versus reactor length.

Conditions: feed temperature: $70^{\circ} \mathrm{C}, 500 \mathrm{~g} / \mathrm{L}$ of $\mathrm{A} 70$ catalyst, $500 \mathrm{~Pa}$ in the permeate and stoichiometric feed ratio, adiabatic reactor. [Color figure can be viewed in the online issue, which is available at wileyonlinelibrary.com.]

independent of the absolute pressure (see Eqs. 1 and 2), it is important to prevent evaporation. Intermediate repressurization between several reactors is likely to be required.

Figure 3 shows that the equilibrium composition is already achieved within the first centimeters of the reactor. This indicates that the water removal via the membrane is, under the current conditions, the rate-determining step. After $\sim 25 \mathrm{~cm}$, the water concentration reaches a maximum and water permeation becomes noticeable. At larger lengths, the acetal concentration increases above the equilibrium value. ${ }^{26}$ The slow, relative to the reaction rate, water depletion can be accelerated by decreasing the reactor diameter to, for example, $20 \mathrm{~mm}$. However, in this case, the criteria of pipe to wall distance of at least eight times the catalyst diameter will not be met, leading to larger inaccuracies in the results. The exothermal reaction causes under the adiabatic conditions, the temperature to increase from 70 to $90^{\circ} \mathrm{C}$ in the first centimeters of the reactor. Further in the reactor of the pervaporation process results in a decreasing temperature to $65^{\circ} \mathrm{C}$. In this case, the process can be considered to be autothermal.

\section{Effect of the temperature}

In these simulations, the inlet temperature was varied between 20 and $70^{\circ} \mathrm{C}$ while keeping the other conditions constant (see Figure 4). The assessed optimal reactor length of $5 \mathrm{~m}$ was selected for all cases. The equilibrium conversion ("A" point in Figure 4) for the initial conditions at each temperature ${ }^{27}$ is reached within the first $50 \mathrm{~cm}$ of the reactor. Only at a reactor length longer than $4 \mathrm{~m}$, the kinetic advantages of applying a higher temperature, that is, faster water removal, become dominant over the thermodynamic disadvantages, that is, lower equilibrium conversion.

\section{Effect of the catalyst}

As discussed above, the pervaporation process is the rate-limiting step. This can also be rebalanced by reducing the amount catalyst. This effect will be studied here in the range from 10 to $550 \mathrm{~g} / \mathrm{L}$ (catalyst bed density). Figure $5 \mathrm{a}$ shows that, at $70^{\circ} \mathrm{C}$, the pervaporation process remains rate determining down to $50 \mathrm{~g} / \mathrm{L}$. Only at a loading level of 10 $\mathrm{g} / \mathrm{L}$ the acetalization reaction becomes the rate-limiting step.

At $20^{\circ} \mathrm{C}$ and a catalyst loading smaller than $150 \mathrm{~g} / \mathrm{L}$, the water partial pressure on the permeate side is calculated to be higher than on the retentate side in the beginning of the reactor. This is a commonly observed consequence of the assumption that the permeate side behaves as a perfect mixed compartment. Thus, the water partial pressure is the same over the whole reactor length. The low temperature and low catalyst loading leads to slow formation of water and thus a low water partial pressure at the initial phase of the reaction. As a result, the driving force for the water transport is in this part of the reactor negative. It is clear that at lower operating temperatures the catalyst loading is more critical than at higher temperatures.

\section{Effect of the component permeance}

In the previous sections, it was concluded that the highest conversions of $\sim 75 \%$ could only be achieved with a reactor length of $15 \mathrm{~m}$ to treat $7 \mathrm{~L} / \mathrm{h}$ of feed flow, which seems to be excessive. This length can be reduced, if the water permeance is increased while keeping the selectivities constant, that is, the permeances of all components were multiplied by the same factor. The reactor length could be reduced from $15 \mathrm{~m}$ to $8,3.3,2.9$, and $2.6 \mathrm{~m}$, if the permeances were increased with a factor of 2, 3, 4, and 5, respectively. This shows that an enhancement with more than a factor 3 is of limited interest.

\section{Effect of the feed composition}

To increase the conversion further the influence of an excess of ethanol, ranging from 2:1 to $4: 1$, as a reactant was studied. Ethanol was selected over butanal because of its

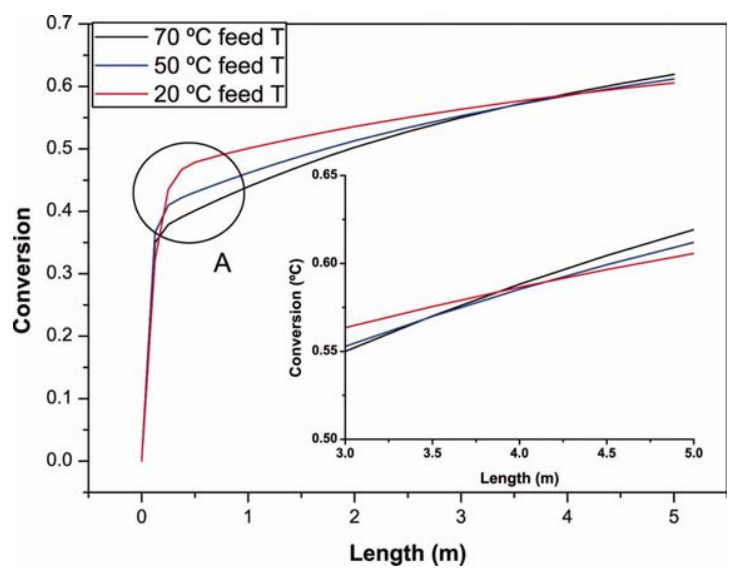

Figure 4. Effect of the temperature on the conversion along the reactor.

Conditions: adiabatic mode with a stoichiometric feed ratio, $500 \mathrm{~Pa}$ in the permeate side and with $500 \mathrm{~g} / \mathrm{L}$ of catalyst loading (A70). [Color figure can be viewed in the online issue, which is available at wileyonlinelibrary.com.] 

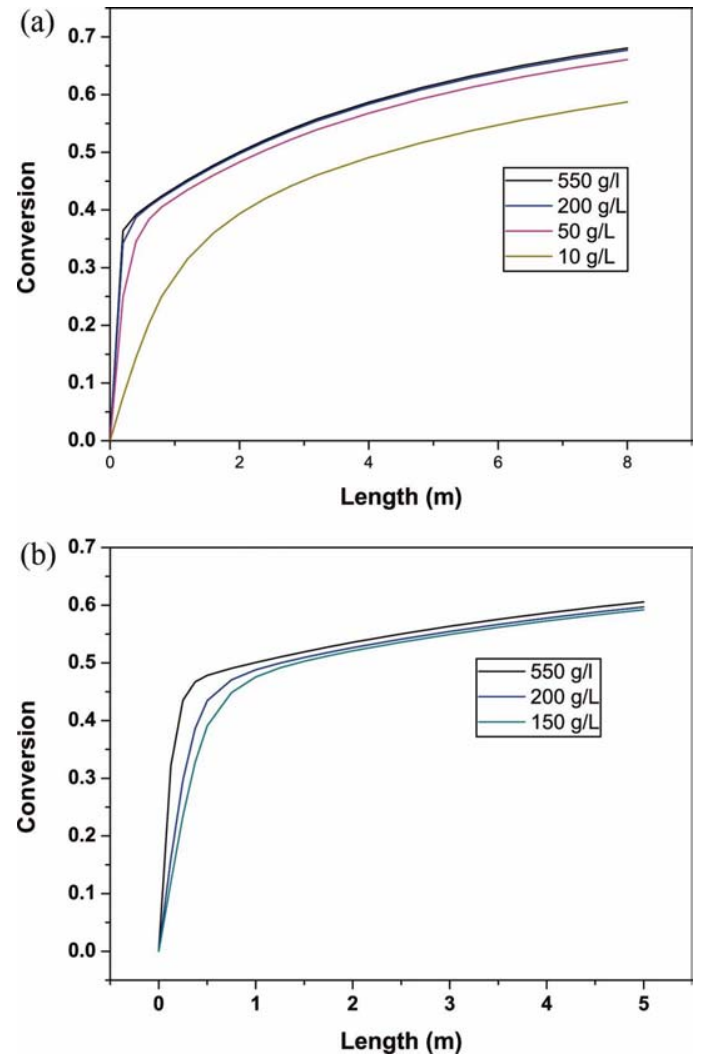

Figure 5. Effect of the catalyst loading on the conversion along the reactor.

Feed temperature (a) $70^{\circ} \mathrm{C}$ and (b) $20^{\circ} \mathrm{C}$. [Color figure can be viewed in the online issue, which is available at wileyonlinelibrary.com.]

lower price level. However, an important loss is expected because of the fairly high permeance. All the calculations were performed at $70^{\circ} \mathrm{C}$ as feed temperature, and $50 \mathrm{~g} / \mathrm{L}$ of catalyst loading and a reactor length of $8 \mathrm{~m}$. The total flow of $7 \mathrm{~L} / \mathrm{h}$ was kept constant for all ethanol to butanal ratios. The conversion increases with $\sim 20 \%$ when going from a feed ratio of $2: 1$ to $4: 1$. At the same time, the ethanol molar fraction in the permeate increases from $\sim 0.06$ to $\sim 0.09$. So for this case, the acetal conversion increases considerably with an acceptable additional ethanol loss.

\section{Effect of a recycle loop}

In the evaluation above, Configuration 1 was used as a basis. Configuration 2 offers promising conversions values $(66 \%)$ at really low Re values. Significant effects from concentration polarization are likely to occur, leading to a lower membrane performance. One possible way to overcome this issue is the use of a recycle loop. By recycling part of the reactor output, the total flow rate in the reactor will increase, allowing higher Re numbers. However, the overall conversion is expected to decrease.

By recycling $90 \%$ of the retentate acceptable $\operatorname{Re}$ values were achieved but the conversion decreased from $66 \%$ to only $12 \%$. By increasing the recycle ratio the residence time decreases, and for this reason the length of the MPFMR was increased from 1 to $8 \mathrm{~m}$. As a result, the conversion increased to $21 \%$. This low value can be ascribed to the presence of acetal in the (recycled) feed decreasing the ethanol and butyraldehyde concentrations, and thus increasing the reverse reaction. In short, recycling part of the retentate, as solution to increase the Re number, is not an option.

\section{Conclusions}

In this paper, the optimal reactor configuration and operation in terms of feed temperature and composition, catalyst loading, membrane performance, and reactor length have been explored. It was found that the catalyst is highly active and that, at higher temperatures, a loading above $50 \mathrm{~g} / \mathrm{L}$ has no added value. Considerable more room for improvement was found for the membrane. The selectivity appeared to be sufficiently high as the ethanol losses were limited. However, the required surface area for an integrated pervaporation membrane reactor proved to be very high, resulting in an unacceptably high pressure drop. A permeance increase with a factor of three was required to come to reasonable reactor length. An alternative solution can be to uncouple reaction and separation. Several units of alternating reaction beds and pervaporation modules may result in lower pressure drops and an optimal freedom for the design of a feasible process.

\section{Acknowledgments}

The authors gratefully acknowledge the financial support of this work by the Spanish Ministry of Science and Innovation (ENE2009-12743C04-04), the Basque Government and the University of the Basque Country (UPV/EHU). Besides, the authors want to mention the collaboration of Rohm \& Haas for kindly supplying different Amberlyst resins.

\section{Notation}

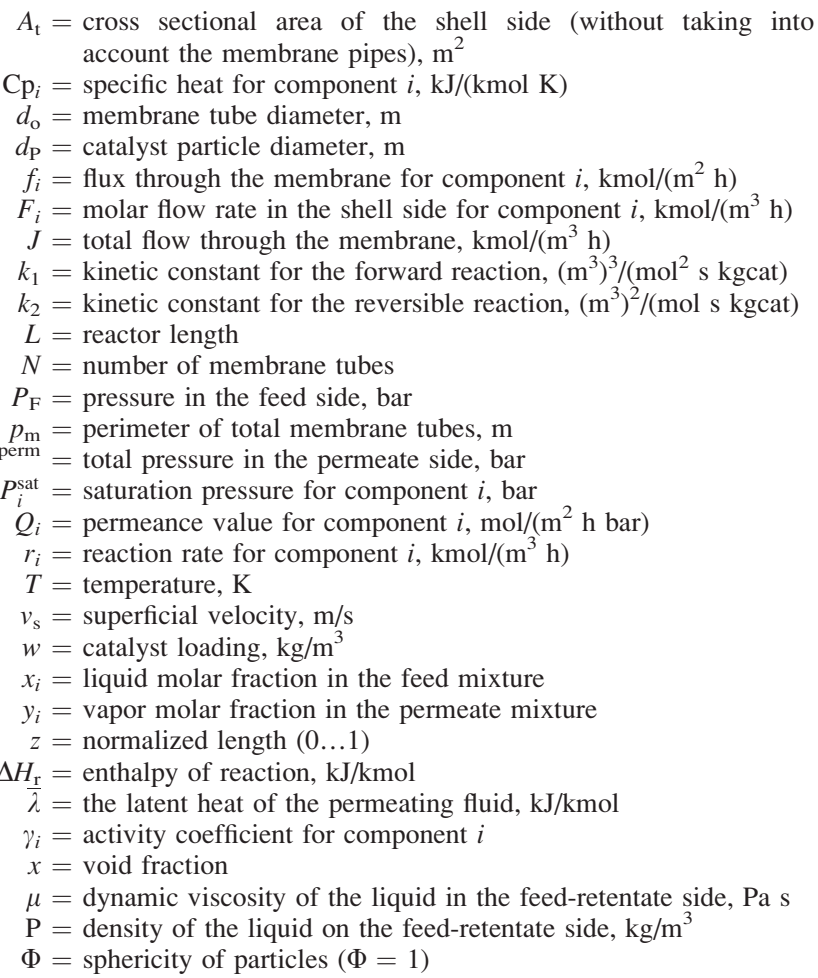




\section{Literature Cited}

1. Capeletti MR, Balzano L, de la Puente G, Laborde M, Sedran U. Synthesis of acetal (1,1-diethoxyethane) from ethanol and acetaldehyde over acidic catalysts. Appl Catal A. 2000;198:L1-L4.

2. Frusteri F, Spadaro L, Beatrice C, Guido C. Oxygenated additives production for diesel engine emission improvement. Chem Eng J. 2007; 134:239-245.

3. Kaufhold M, El-Chahawi M, inventors. Huels Aktiengesellschaft, assignee. Process for preparing acetaldehyde diethyl acetal. Germany patent 5527969, June 18, 1996.

4. Green TW. Protective Groups in Organic Synthesis. New York: Willey, 1981.

5. Sharma MM. Some novel aspects of cationic ion-exchange resins as catalysts. React Funct Polym. 1995;26:3-23.

6. Mahajani SM, Kolah AK, Sharma MM. Extractive reactions with cationic exchange resins as catalysts (acetalization of aldehydes with alcohols). React Funct Polym. 1995;28:29-38.

7. Chopade SP, Sharma MM. Acetalization of ethylene glycol with formaldehyde using cation-exchange resins as catalysts: batch versus reactive distillation. React Funct Polym. 1997;34:37-45.

8. Chopade SP, Sharma MM. Reaction of ethanol and formaldehyde: use of versatile cation-exchange resins as catalyst in batch reactors and reactive distillation columns. React Funct Polym. 1997;32:53-65.

9. Zhu Y, Minet RG, Tsotsis TT. A continuous pervaporation membrane reactor for the study of esterification reactions using a composite polymeric/ceramic membrane. Chem Eng Sci. 1996;51:4103-4113.

10. Feng X, Huang RYM. Studies of a membrane reactor: esterification facilitated by pervaporation. Chem. Eng. Sci. 1996;51:4673-4679.

11. Lim Y, Park B, Hung F, Sahimi M, Tsotsis T. Design issues of pervaporation membrane reactors for esterification. Chem. Eng. Sci. 2002;57:4933-4946.

12. Domingues L, Recasens F, Larrayoz MA. Studies of a pervaporation reactor: kinetics and equilibrium shift in benzyl alcohol acetylation. Chem. Eng. Sci. 1999;54:1461-1465.

13. Benedict DJ, Parulekar SJ, Tsai SP. Esterification of lactic acid and ethanol with/without pervaporation. Ind Eng Chem Res. 2003;42: 2282-2291.

14. Sanz MT, Gmehling J. Esterification of acetic acid with isopropanol coupled with pervaporation: Part I. Kinetics and pervaporation studies. Chem. Eng. J. 2006;123:1-8.

15. Sanz MT, Gmehling J. Esterification of acetic acid with isopropanol coupled with pervaporation: Part II. Study of a pervaporation reactor. Chem Eng J. 2006;123:9-14.

16. Sanchez Marcano JG, Tsotsis Th.T. Catalytic Membrane and Membrane Reactors. Weinheim: Wiley, 2002.

17. Drioli E, Giorno L. Comprehensive Membrane Science and Engineering, 1st ed. Amsterdam: Elsevier Science, 2010.

18. Hazarika S, Dutta A, Dutta N. Pervaporation aided esterification of carboxylic acids with ethanol catalyzed by porcine pancreatic lipase. Biocatal Biotransform. 2003;21:101-113.

19. Izak P, Mateus NMM, Afonso CAM, Crespo JG. Enhanced esterification conversion in a room temperature ionic liquid by integrated water removal with pervaporation. Sep Purif Technol. 2005;41:141-145.
20. Wasewar K, Patidar S, Agarwal VK. Esterification of lactic acid with ethanol in a pervaporation reactor: modeling and performance study. Desalination. 2009;243:305-313.

21. Wasewar KL. Modeling of pervaporation reactor for benzyl alcohol acetylation. Int J Chem React Eng. 2007;5:A6.

22. Tanna NP, Mayadevi S. Analysis of a membrane reactor: influence of membrane characteristics and operating conditions. Int $\mathrm{J}$ Chem React Eng. 2007;5:A5.

23. de la Iglesia O, Mallada R, Menendez M, Coronas J. Continuous zeolite membrane reactor for esterification of ethanol and acetic acid. Chem Eng J. 2007;131:35-39.

24. Nemec D, Van Gemert R. Performing esterification reactions by combining heterogeneous catalysis and pervaporation in a batch process. Ind Eng Chem Res. 2005;44:9718-9726.

25. Agirre I, Barrio VL, Güemez B, Cambra JF, Arias PL. Catalytic reactive distillation process development for 1,1 diethoxy butane production from renewable sources. Bioresour Technol. 2011;102:1289-1297.

26. Agirre I, Guemez MB, Motelica A, van Veen HM, Vente JF, Arias PL. Acetalization reaction of ethanol with butyraldehyde coupled with pervaporation. Semi-batch pervaporation studies and resistance of $\mathrm{HybSi}{ }^{\circledR}$ membranes to catalyst impacts. $J$ Membr Sci. 2011;371:179-188.

27. Agirre I, Barrio VL, Güemez B, Cambra JF, Arias PL. The development of a reactive distillation process for the production of 1,1 diethoxy butane from bioalcohol: kinetic study and simulation model. Int J Chem React Eng. 2010;8:A86.

28. Baker RW. Membrane Technology and Applications, 2nd ed. Chichester: Wiley, 2000.

29. Nunes SP, Peinemann KV. Membrane Technology in Chemical Industry. Weinheim: Wiley, 2001.

30. Prausnitz JM, Polling BE, O'Connell JP. The Properties of Gases and Liquids, 5th ed., New York: McGraw-Hill, 2007.

31. Letcher TM, Redhi GG, Radloff SE. Liquid-Liquid Equilibria for Mixtures of Butanal + an Alkanol + Water at 298.15 K. J Chem Eng. 1996;41:707-712.

32. NIST Chemistry Webbook. http://webbook.nist.gov/chemistry/ 2009.

33. Geankoplis CJ. Transport Processes and Separation Process Principles, 3rd ed. México: Compañia Editorial Continental, S.A de C.V., 1998.

34. Theuerkauf J, Witt P, Schwesig D. Analysis of particle porosity distribution in fixed beds using the discrete element method. Powder Technol. 2006;165:92-99.

35. Dixon AG. Correlations for wall and particle shape effects on fixed bed bulk voidage. Can J Chem Eng. 1988;66:705-708.

36. Sommer S, Klinkhammer B, Schleger M, Melin T. Performance efficiency of tubular inorganic membrane modules for pervaporation. AIChE J. 2005;51:162-177.

37. Perry RH, Green DW. Perry's Chemical Engineers' Handbook, 8th ed. New York: McGraw Hill, 2007.

38. Froment GF. Chemistry and Chemical Engineering of Catalytic Process, 1st ed. Maryland: Springer, 1980.

39. Albright's Chemical Engineering Handbook. Boca Raton, FL: (Florida, USA): CRC Press, Taylor \& Francis Group, 2008.

Manuscript received Mar. 17, 2011, and revision received May 19, 2011 